\title{
Enraizamento de estacas semilenhosas de pessegueiro “Okinawa” sob efeito de lesão e ácido indolbutírico
}

\author{
Semi-hardwood cuttings rooting of peach tree 'Okinawa' under effect of lesion and indolebutyric acid
}

\author{
Mara Rubia Camolesi' Lilian Keiko Unemoto ${ }^{\text {II }}$ Paula Jimena Diniz Sachs ${ }^{\text {II }}$ Sergio Ruffo Roberto ${ }^{\text {III }}$ \\ Alessandro Jefferson Sato ${ }^{\text {II }}$ Anderson Paranzini FariaII Euripedes Bomfim Rodrigues ${ }^{\text {II }}$ \\ Joelson Vieira da SilvaII
} \begin{abstract}
Buscando técnicas mais eficientes na propagação
de mudas de pessegueiro, desenvolveu-se este trabalho com o objetivo de verificar o efeito da lesão e de diferentes concentrações de ácido indolbutírico (AIB) no enraizamento de estacas semilenhosas do pessegueiro "Okinawa". Foram utilizados dois tipos de estacas (com e sem lesão na base), tratadas por imersão da base por cinco segundos em cinco concentrações de AIB (0, 500, 1.000, 1.500 e 2.000mg L $\left.\mathrm{L}^{-1}\right)$. Após o tratamento, as estacas foram colocadas para enraizamento em caixas plásticas, contendo casca de arroz carbonizada, em câmara de nebulização. Após 60 dias do início do experimento, verificou-se que a lesão na base proporcionou aumento da porcentagem de estacas enraizadas e do número de raízes por estaca. Na propagação por estaquia semilenhosa de pessegueiro "Okinawa", os melhores resultados foram observados para estacas que sofreram lesão e que foram tratadas com AIB em concentrações de 1.500 e $2.000 \mathrm{mg} \mathrm{L}^{-1}$.
\end{abstract}

Palavras-chave: Prunus persica, propagação, estaquia, regulador de crescimento.

\section{ABSTRACT}

In search of more efficacious techniques in peach plant propagation, this research was aimed at verifing the effect of the lesion and different concentrations of indolbutiric acid (IBA) on rooting of semi-hardwood cuttings rooting of the 'Okinawa' peach. A randomized design was used arranged on a $2 \times 5$ factor with 4 repetitions and 8 cuttings for plot. Two types of cuttings were used (with and without lesion in the base) and five concentrations of IBA $(0 ; 500 ; 1000 ; 1500$ and $\left.2000 \mathrm{mg} \mathrm{L}^{-1}\right)$. After 60 days from the beginning of the experiment, it was verified that the base injury leads to an increase in the percentage of root cuttings and in the number of roots per cuttings. In the semi-hardwood propagation of 'Okinawa' peach, the best results were observed for cuttings with lesion that were treated with IBA in concentrations ranging from 1500 to $2000 \mathrm{mg} \mathrm{L}^{-1}$.

Key words: Prunus persica, propagation, stake, growth regulator.

No Brasil, o pessegueiro (Prunus persica (L.) Batsch) é cultivado principalmente na região Sul, sendo propagado por meio da enxertia de borbulhas de cultivares-copa em porta-enxertos oriundos de sementes (TONIETTO et al., 1997). Esta técnica possibilita a ocorrência de polinização cruzada e a ocorrência de segregação e perda de caracteres agronômicos desejáveis (FACHINELLO et al., 1982).

A propagação do porta-enxerto por estacas apresenta como vantagens a uniformidade e a facilidade de produção da muda (CHALFUN \& HOFFMANN, 1997), porém, muitas vezes, não é empregada devido, principalmente, aos baixos percentuais de enraizamento obtidos pela maioria das cultivares e à falta de informação existente sobre o

\footnotetext{
ILaboratório de Cultivo in vitro-BIOMAVALE. Rua Dr. Geraldo Nogueira Leite, 1735, Assis, SP, Brasil. E-mail: mrcamol@femanet.com.br. Autor para correspondência.

IIPrograma de Pós-graduação em Agronomia, Universidade Estadual de Londrina (UEL), Londrina, PR, Brasil.

IIIDepartamento de Agronomia, Centro de Ciências Agrárias, UEL, Londrina, Paraná, Brasil.
} 
comportamento destas estacas no campo (TOFANELLI et al., 2004).

Várias técnicas têm sido utilizadas na tentativa de aumentar a capacidade na formação de raízes adventícias em estacas, como a aplicação exógena de fitorreguladores (TOFANELLI et al., 2004), que têm por finalidade induzir o processo rizogênico, aumentando a porcentagem de estacas que formam raízes, o número e a qualidade das raízes formadas, bem como a uniformidade no enraizamento. O ácido indolbutírico (AIB) tem sido o mais utilizado para esse fim(MIRANDA et al., 2003).

O índice de enraizamento também pode ser aumentado por meio de lesão na base das estacas. Para FACHINELLO et al. (1995), a lesão permite que haja o rompimento da barreira física exercida pelos anéis de esclerênquima, além do aumento da taxa respiratória e dos teores de auxina, carboidratos e etileno na área lesionada.

Este trabalho teve como objetivo avaliar o efeito da lesão e do ácido indolbutírico no enraizamento de estacas semilenhosas de pessegueiro “Okinawa”.

Utilizaram-se estacas de ramos semilenhosos, coletados no início do outono, de plantas do pessegueiro "Okinawa” com aproximadamente três anos de idade, pertencentes ao BAG - Banco Ativo de Germoplasma da Universidade Estadual de Londrina, Paraná. As estacas foram padronizadas com aproximadamente $15 \mathrm{~cm}$ de comprimento e quatro folhas com as pontas cortadas para evitar que entrassem em contato com o substrato.

Foram feitos dois cortes longitudinais opostos na base da estaca com aproximadamente $1 \mathrm{~cm}$ de comprimento e 2mm de profundidade. Em seguida, a porção basal passou por imersão rápida (5 segundos) em soluções de 0; 500; 1000; 1500 e 2000 $\mathrm{mg} \mathrm{L}^{-1}$ de AIB, sendo as estacas imediatamente acondicionadas, para enraizamento, em caixas plásticas contendo casca de arroz carbonizada, em câmara de nebulização intermitente controlada por temporizador e válvula solenóide. O bico nebulizador (Modelo Mist Dan Sprinklers, Israel) apresentava vazão de $35 \mathrm{~L} \mathrm{~h}^{-1}$. O sistema de nebulização foi programado para acionar durante 10 segundos a cada intervalo de três minutos, e encontrava-se no interior de estufa agrícola com cobertura de filme de polietileno transparente e sombrite $30 \%$, temperatura de $25^{\circ} \mathrm{C}$ e umidade relativa de $75 \%$.

O delineamento experimental foi 0 inteiramente casualizado, com quatro repetições em arranjo fatorial $2 \times 5$ (com e sem lesão e cinco concentrações de AIB), sendo cada parcela composta por oito estacas. Para o controle de doenças fúngicas, as estacas foram pulverizadas semanalmente com benomyl 1\%. Após 60 dias, avaliou-se a porcentagem de estacas enraizadas, o número de raízes por estaca, o comprimento de raízes, a porcentagem de estacas mortas, a massa fresca e a massa seca das raízes, avaliada esta após secagem por 48 horas a $68^{\circ} \mathrm{C}$ em estufa com ventilação forçada. Foi avaliado o efeito dos fatores (lesão e AIB) através do teste de Tukey a 5\% de significância, e os níveis de AIB por meio de análise de regressão.

Verificou-se que a porcentagem de estacas enraizadas foi maior para estacas com lesão. Em ambos os tipos de estacas, a porcentagem de enraizamento foi crescente até aproximadamente a concentração de $1.500 \mathrm{mg} \mathrm{L}^{-1}$ de AIB (Figura 1a). O ponto de máxima eficiência de AIB para as estacas com lesão foi na concentração de $1.427 \mathrm{mg} \mathrm{L}^{-1}$, e na de $1.671 \mathrm{mg} \mathrm{L}^{-1}$ para as estacas sem lesão. TOFANELLI et al. (2003a) observaram que as maiores porcentagens de enraizamento da cultivar "Okinawa” foram obtidas em concentrações de AIB acima de $1.250 \mathrm{mg} \mathrm{L}^{-1}$, com máximo em 2.500 $\mathrm{mg} \mathrm{L}^{-1}$. SOUZA et al. (1995) observaram que a lesão na base da estaca de ameixeira (Prunus salicina) aumentou o porcentual de enraizamento de 54,5\% (sem lesão) para 81,7\% (com lesão).

Para a característica número de raízes por estaca, foi observada a superioridade das estacas com lesão na formação de raízes em relação às estacas sem lesão (Figura 1b), com um crescimento linear na proporção de raízes formadas em relação ao aumento da concentração de AIB. MIRANDA et al. (2003) verificaram que o tratamento com AIB na concentração de 4.000 $\mathrm{mg} \mathrm{L}^{-1}$, em estacas lenhosas de pessegueiro “Okinawa”, resultou em 10,33 raízes e, quando não tratadas, produziu apenas 1 raiz por estaca.

Em relação às massas fresca e seca de raízes por estaca, observou-se acréscimo, com o aumento das concentrações de AIB (Figura 1c e 1d). As estacas lesionadas apresentaram maiores médias de massa fresca e seca, até as concentrações de $1.500 \mathrm{mg} \mathrm{L}^{-1} \mathrm{e}$ $1.750 \mathrm{mg} \mathrm{L}^{-1}$ de AIB, respectivamente. BIASI et al. (2000), em estudos com cultivares de pessegueiro e nectarineira, observaram aumento de volume e massa fresca de raízes, em função do aumento da concentração de AIB, até $2.000 \mathrm{mg} \mathrm{L}^{-1}$.

Para a porcentagem de estacas mortas (Tabela 1), foi observada diferença significativa apenas para estacas com lesão e sem imersão em AIB $\left(0 \mathrm{mg} \mathrm{L}^{-1}\right)$ com $96 \%$. Todas as outras concentrações de AIB para os dois tipos de estaquia não apresentaram diferenças, demonstrando que a lesão é prejudicial na ausência de AIB.

Para o comprimento de raízes (Tabela 1), houve efeito positivo da imersão em $500 \mathrm{mg} \mathrm{L}^{-1}$ de AIB 

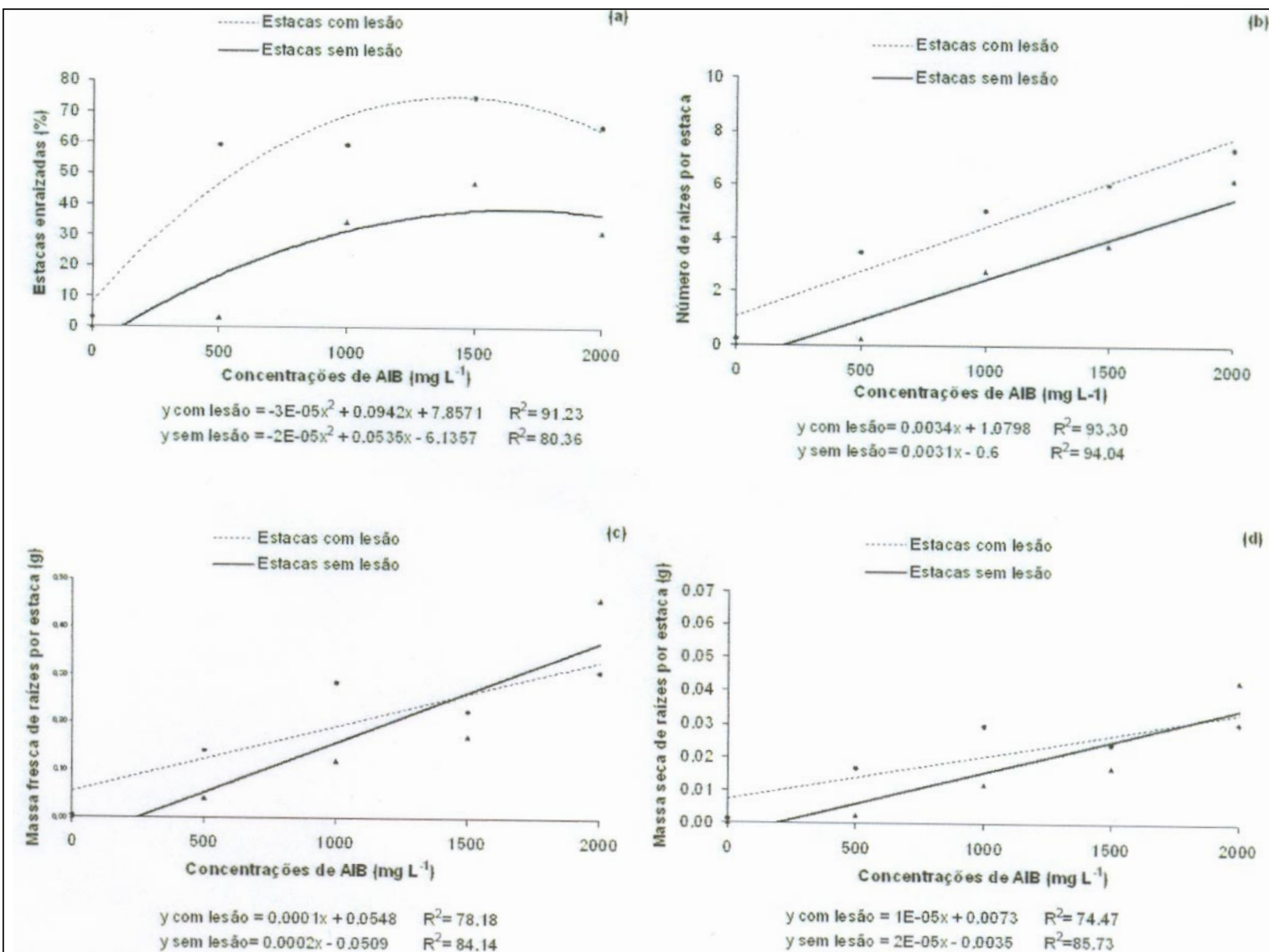

Figura 1 - Estacas enraizadas (a), número de raízes por estaca (b), massa fresca (c) e massa seca por estaca (d) de pessegueiro "Okinawa” tratadas com ácido indolbutírico (AIB). Londrina, PR, 2005.

Tabela 1 - Influência da concentração de AIB e do tipo de estaquia na pocentagem de estacas mortas e no comprimento de raízes de estacas semilenhosas do pessegueiro “Okinawa” UEL, Londrina, PR, 2005.

\begin{tabular}{|c|c|c|c|}
\hline \multirow{2}{*}{ Parâmetros } & \multirow{2}{*}{ Concentrações de AIB $\left(\mathrm{mg} \mathrm{L}^{-1}\right)$} & \multicolumn{2}{|c|}{ Tipo de estaquia } \\
\hline & & Sem lesão & Com lesão \\
\hline \multirow{5}{*}{ Estacas mortas } & 0 & $0,0 \mathrm{aB}$ & $6,3 \mathrm{aA}$ \\
\hline & 500 & $6,3 \mathrm{aA}$ & $12,5 \mathrm{aA}$ \\
\hline & 1000 & $3,1 \mathrm{aA}$ & $9,4 \mathrm{aA}$ \\
\hline & 1500 & $15,6 \mathrm{aA}$ & $3,1 \mathrm{aA}$ \\
\hline & 2000 & $12,5 \mathrm{aA}$ & 21,9aA \\
\hline \multirow[t]{3}{*}{ CV (\%) } & & 117,44 & \\
\hline & 0 & $0,0 \mathrm{cA}$ & $0,4 \mathrm{bA}$ \\
\hline & 500 & $0,9 \mathrm{bcB}$ & $2,8 \mathrm{aA}$ \\
\hline \multirow[t]{3}{*}{ Comprimento de raízes $(\mathrm{cm})$} & 1000 & 2,7abA & $3,4 \mathrm{aA}$ \\
\hline & 1500 & 2,5abA & $2,8 \mathrm{aA}$ \\
\hline & 2000 & $4,3 \mathrm{aA}$ & $2,9 \mathrm{aB}$ \\
\hline CV (\%) & & 43,60 & \\
\hline
\end{tabular}

Médias seguidas pelas mesmas letras maiúsculas nas linhas e minúsculas nas colunas não diferem entre si pelo teste de Tukey $(\mathrm{P}<0,05)$.

Ciência Rural, v.37, n.6, nov-dez, 2007. 
para estacas com lesão, porém não houve diferença em concentrações superiores, sugerindo que a imersão de estacas com lesão na menor concentração de AIB já é suficiente para induzir maior comprimento de raízes.

Na propagação por estaquia semilenhosa de pessegueiro "Okinawa”, os melhores resultados foram observados para estacas que sofreram lesão e que foram tratadas com ácido indolbutírico nas concentrações de 1500 e $2000 \mathrm{mg} \mathrm{L}^{-1}$.

\section{REFERÊNCIAS}

BIASI, L.A. et al. Estaquia de ramos semilenhosos de pessegueiro e nectarina. Revista Brasileira de Fruticultura, v.22, p.421425, 2000.

CHALFUN, N.N.J.; HOFFMANN, A. Propagação do pessegueiro e da ameixeira. Informe Agropecuário, v.18, p.23-29, 1997.

FACHINELLO, J.C. et al. Efeito do ácido indolbutírico no enraizamento de estacas lenhosas de Pessegueiro cv. "Diamante".
Pesquisa Agropecuária Brasileira, v.17, p.247-252, 1982.

FACHINELLO, J.C. et al. Propagação de plantas frutíferas de clima temperado. 2.ed. Pelotas: UFPEL, 1995. 178p.

MIRANDA C.S. et al. Enxertia recíproca e AIB como fatores indutores do enraizamento de estacas lenhosas dos portaenxertos de pessegueiro "Okinawa" e umezeiro. Ciência e Agrotecnologia, v.28, p.778-784, 2003.

SOUZA, C. et al. Efeito da lesão e do ácido indolbutírico no enraizamento de duas cultivares de ameixeira (Prunus salicina, Lindl) através de estaca. Revista Brasileira de Agrociência, v.1, p.171-174, 1995

TOFANELLI, M.B.D. et al. Método de aplicação do ácido indolbutírico na estaquia de cultivares de pessegueiro. Ciência e Agrotecnologia, v.27, p.1031-1037, 2003a.

TOFANELLI, M.B.D. et al. 2,6-Di-hidroxiacetofenona no enraizamento de estacas semilenhosas de pessegueiro. Revista Brasileira de Fruticultura, v.26, p.366-368, 2004.

TONIETTO, A. et al. Influência do ácido indolbutírico e ethephon no enraizamento de estacas de pessegueiro (Prunus persica (L.) Batsch). Ciência Rural, v.27, p.567-569, 1997. 